\title{
Teaching children about self-protection from sexual abuse: could it be a cause for source monitoring errors and fantasy? (Two case reports)
}

Dalia Mohammed Alsaif, Osama M. Almadani, Salah Ali Almoghannam, Maram A. Al-Farayedhi and Magdy A. Kharoshah

\begin{abstract}
Background: Child sexual abuse, being most of the time a hidden crime that is kept lifelong undisclosed, was found to have strong influence on the victim. Unless a hard evidence (physical evidence, eyewitness, perpetrator confession) was present, decision on the case will depend solely on the child's account. In spite of efforts to get accurate information, children tend to mix events they have experienced with those seen on $T V$, heard in a story or even introduced by others while questioning about the event. Source monitoring error is the error in tagging information to its source and is a problem faced when interviewing very young children and when repeatedly rehearsing a false event. In Saudi Arabia, awareness programs were initiated and were distributed widely to educate families about consequences of abuse and the available facilities to seek if needed. These programs took part in social campaigns at malls, schools and media. Parents became more aware of the problem and concerned parents even took part in educating their children about self protection. Knowing that formal sexual health education is deficient in Saudi Arabia and in other Arab countries can put such programs in challenge.
\end{abstract}

Case presentation: In this paper, two cases are presented of child sexual abuse allegations that raised the issue of source monitoring errors in children with over concerned mothers. The mothers admitted the fact that they are giving extensive detailed teaching to their girls about the sexual abuse. The possibilities of having source monitoring errors are discussed while highlighting the protocols of forensic interview and methods to minimize source monitoring errors.

Conclusion: Teaching self protection against sexual abuse could be the first introduction of sexual issues to children and hence could lead to source monitoring errors and false allegation of child sexual assault.

Keywords: Child sexual abuse, Forensic interview, Source monitoring error, Sexual health education

\footnotetext{
* Correspondence: alsaifd@yahoo.com

Center of Forensic and Legal Medicine, P.O. Box 1127, Dammam, Eastern

Province, Saudi Arabia
} 


\section{Background}

Child abuse has gained worldwide attention in the past few decades. Scientific studies have been conducted to unveil the true magnitude of the problem, including the rates, motivations of the perpetrator, consequences on the child, and how to manage this global issue (Stoltenborgh et al., 2011; Pereda et al., 2009; Kenny \& McEachern, 2000; Finkelhor, 1994). One of the largest studies that settled a strong link between bad childhood experiences and future physical and psychological derangements of the abused child is the adverse childhood experiences (ACE) study (Varese et al., 2012). This study was conducted in several countries and in Saudi Arabia it revealed that ACE increased the risk to hypertension, diabetes mellitus, psychological disease, and dysfunctional lives (Almuneef et al., 2014).

Sexual abuse was found to have more influence on the victim, one reason being that this is mostly a hidden crime that is kept undisclosed throughout the victim's life (Bottoms et al., 2002). Having this secrecy makes it even more difficult for the legal system to investigate and unless hard evidence (physical evidence, eyewitness or perpetrator confession) was present, any decision on the case will depend solely on the child's account. The process of forensically interviewing the child to get information related to the assault was investigated and evaluated over time and several experiments were conducted to examine the child's memory to find the best way of eliciting reliable and accurate information. It was found that age of the child, language, reasoning, knowledge, and emotional maturity all affect responses to adults' questions (Saywitz \& Camparo, 1998). While no single forensic interview is considered perfect, efforts were made to set rules of forensic interviews in a single protocol with the aim of increasing reliability of information. Many protocols were constructed and studied; however, the National Institute of Child Health and human Development (NICHD) protocol increased the reliability in decisions made by investigators and hence led to more assurance of delivery of justice (Hershkowitz et al., 1996).

NICHD protocol is a stepwise forensic interviewing protocol that enhances free-recall memory while minimizing eliciting information from recognition memory. It uses cued invitations, time segmentation, anchoring, and facilitations to increase free disclosure of accurate details of the event (Orbach et al., 2000; Lamb et al., 2007; Dion \& Cyr, 2008). In spite of efforts to get accurate information, children tend to mix events they have experienced with those seen on TV, heard in a story, or even introduced by others while questioning about the event. Source monitoring error is the error in tagging information to its source and is a problem faced when interviewing very young children and when the child repeatedly rehearse a false event (Roberts \& Powel, 2001). Participation of the child in the event increases accuracy of free recalled information and decreases suggestibility (Tobey \& Goodman, 2010).

In Saudi Arabia, laws have been enacted to require all professionals to report any case of suspected child abuse or neglect and programs were initiated to educate professionals about this issue (Al Eissa \& Almuneef, n.d.; Pietrantonio et al., 2013). Parallel to this, awareness programs were initiated and were distributed widely to educate families about the consequences of child sexual abuse and the available facilities to seek if needed. These programs took part in social campaigns at malls, schools, and in the media. Educating children about self protection was mandated in schools and those programs increased at an accelerated rate with many professionals taking part in these programs. Parents became more aware of the problem and concerned parents even took part in educating their children about self protection. Schools in Saudi Arabia are deficient in education programs about sexual health and teaching self protection from sexual assault might be the first introduction to the children about this issue (AlQuaiz et al., 2012; AlQuaiz et al., 2013). This way of educating children about self protection from sexual abuse could lead to adverse effects if not given in the proper way from well-experienced persons.

In this paper, the authors present two cases of sexual abuse allegations that raised the issue of source monitoring errors in children with over-concerned mothers who gave extensively detailed teaching to their girls about the problem of sexual abuse.

\section{Case presentation \\ Case 1}

A five-year-old girl presented with her mother to the child protective committee in the children's hospital and was examined by a forensic medical examiner after bringing a police report of a suspected sexual assault. The girl was interviewed by the forensic examiner following the NICHD forensic interview protocol and she stated that a boy hurt her private parts and she bled from this area two days prior to her presentation, but she didn't give details of the assault. The mother gave a history of the girl accompanying her aunt to a party where the girl was playing with a boy and a girl of the same age.

The police investigated and found that there was an accidental fall of her friend while she was playing with the boy with injury to her ear and bleeding at the same place.

The mother spontaneously said that she always warned her daughter about being touched by others and explained to her in details how bad people could hurt her at her at private parts of body. The mother was previously concerned about the occurrence of such an incident to her daughter. Forensic medical evaluation reported normal body and genital examination with no recent or past 
injuries. Samples for Forensic evidence were not collected and the case was closed by the police.

\section{Case 2}

A nine-year-old girl presented with her mother to the forensic medicine clinic with a police report of being abused sexually by the school bus driver one week before her presentation. The girl was interviewed with a structured forensic interview and stated that the bus driver went with her to a faraway place and abused her sexually in the bus. She stated that she felt annoyed but refused to give details of the incident although she was openly taking about herself.

The mother spontaneously said that she always talk with her daughters and tell them about sexual abuse and not to be touched by anybody in private body parts. Forensic medical examination was normal with no recent or past injuries in the body or genitals. Forensic evidence samples were not collected because of the long time passed after the alleged incident. The case was investigated by the police but was not substantiated.

\section{Discussion}

Eliciting information from a child who discloses being sexually assaulted is influenced by several factors. The age of the child is one important element; the older the child, the more likely he or she is to disclose and give more details (Sternberg \& Lamb, 1997). Although it might seem difficult to get reliable information from younger age groups, children as young as 4 years old were found to give good central details of the incident (Cederborg, 2004). The presented cases were of 5 and 9 years of age and both of them gave detailed information of circumstances of the incidence using the openended invitations by the interviewer. However, none gave details of the sexual assault. Lack of details could be explained by the shame of talking about this issue, but it can also result from not experiencing the event as participation increases free recall accuracy especially when open ended prompts are used in the interview.

Children in younger age groups tended to mix events that they had experienced with those witnessed on TV or heard from a story. Other sources of information that could intermingle in their minds are those from interviews by others, especially repetitive ones using suggestive questions (Goodman et al., 2002). These are considered source monitoring errors where the child has confusion in tagging an event to its source. In both cases, there was an over-concerned mother who talked with the interviewer about how she was preoccupied with the fear of having her daughter being sexually assaulted. The mothers explained how they taught their girls of how people could hurt them sexually with detailed descriptions of the act, and both of them stressed how they repeatedly warned their girls of this issue. Moreover, both mothers tried to get information from their kids before presenting for evaluation. No one knows if these mothers where themselves victims of sexual assault, as it was not asked directly, but this could be the basis for their over concern.

A study was done in Saudi Arabia and revealed poor sexual health knowledge in the majority of adolescent participants. Formal education does not include sexual education. Children get their sexual information from discussing the matter with friends, mothers, and even the house maids. Media plays a pivotal role in delivering sexual information, although this information many times is inaccurate and culturally competent (AlQuaiz et al., 2012; AlQuaiz et al., 2013). A mother warning her girl of being a victim of sexual assault could be the first exposure of the child to this issue. This could be delivered in the wrong way which can lead to negative results like fear and anxiety of the child. Adding to that, the child could fantasize this information and apply it to her/himself. From the experience of the authors, many worried mothers and other lay persons had already tried to extract information from the child for the possibility of being sexually assaulted before presenting to professionals (Goodman et al., 2002). Mothers introduce specific acts to the child in the process of eliciting information in the way of option-posing questions. They are tapping the recognition memory that is discouraged in systematic forensic interviews as it is known to elicit less accurate data where children are misled by the suggestive questions by adults (Saywitz \& Camparo, 1998; Cederborg, 2004; Orbach \& Lamb, 2001).

Having normal genital examination is expected and doesn't exclude sexual assault. Several studies indicated that most kids who disclosed sexual assault had normal genital examination. Reasons for that include fondling with no real penetration, healed injuries, or in older age groups, tissue elasticity that does not leave any injury (Anderst et al., 2009; Adams et al., 1994; Bays, 1993).

The first case was well investigated; the real incident was clear and the case was closed, while the other case was unsubstantiated. It could be a true case of sexual assault with no hard evidence (perpetrator confession, biological evidence or a witnessed incident), without which the legal authorities finds difficulty deciding on the case. However, lack of details of the sexual act, lack of physical findings, and the presence of a mother who spontaneously showed her worries and introduced in details the sexual assault to the girl and asked her repeatedly about the incident could explain a false allegation with source monitoring error.

Source monitoring errors can be reduced by asking the child directly about the source; this should be used cautiously as the child might feel unbelievable. Also this 
direct questioning is not applicable in very young children. Another way to reduce source monitoring errors is to perform the interview as close as possible to the alleged assault and to ask about the feelings of the child during the assault. A child who sees an incident in the TV or in a story wouldn't have the same feelings as one who experience a real incident (Roberts \& Powel, 2001; Poole \& Dickinson, 2011).

\section{Conclusion}

These two cases could be the ringing bell to draw our attention to the possibility of having source monitoring errors as a result of introduction of sexual education in the wrong way. Actions should be taken to raise awareness about the problem of receiving education about protection from sexual assault from persons with no background on the proper delivery of such information. Recently enacted regulations require all schools to introduce programs teaching the kids how to protect themselves from sexual abuse, and the efforts made by schools to fulfill this requirement are done without paying attention to the qualifications and experiences of the people conducting such programs. Community-based awareness programs also should be initiated to educate parents about the proper way of teaching their kids and getting information, and how to do this if the mother is a victim of child sexual abuse. As recommended by previous studies, culturally oriented and topic-specific sexual education should be initiated at schools, and as the age of puberty for girls is decreasing worldwide, this education needs to start from younger age groups (AlQuaiz et al., 2012; AlQuaiz et al., 2013).

Until we have a national study that could reveal the presence and the magnitude of this problem (source monitoring errors as a result of false delivery of sexual assault protection programs), these two cases will remain an example for each professional conducting forensic interviews to be broad minded and allow other explanations for any story that is heard from a child.

\section{Abbreviations}

ACE: Adverse childhood experiences; NICHD: National institute of child health and human development; TV: Television

Funding

Not applicable.

\section{Availability of data and materials}

Not applicable.

\section{Authors' contributions}

All authors contributed to the literature review, Data collection and writing the manuscript.

\section{Ethics approval and consent to participate}

Not applicable.

\section{Consent for publication}

Consent was taken from parents to publish patient details.

\section{Competing interests}

Magdy Kharoshah is the Editor-in-Chief for the Egyptian Journal of Forensic Sciences, but played no part in the peer review process of this article. All other authors declare that they have no competing interests.

\section{Publisher's Note}

Springer Nature remains neutral with regard to jurisdictional claims in published maps and institutional affiliations.

Received: 9 May 2017 Accepted: 6 March 2018

Published online: 12 March 2018

\section{References}

Adams JA, Harper K, Knudson S, Revilla J (1994) Examination findings in legally confirmed child sexual abuse: it's normal to be normal. Pediatrics 94(3):310-317

Al Eissa M, Almuneef M (2010) Child Abuse and Neglect in Saudi Arabia: Journey of Recognition to Implementation of National Prevention Strategies. Child Abuse Negl 34(1):28-33

Almuneef M, Qayad M, Aleissa M, Albuhairan F (2014) Adverse childhood experiences, chronic diseases, and risky health behaviors in Saudi Arabian adults: A pilot study. Child Abuse Negl 38(11):1787-1793

AlQuaiz AJM, Al Muneef M, Minhas HR (2012) Knowledge, attitudes, and resources of sex education among female adolescents in public and private schools in Central Saudi Arabia. Saudi Med J 33(9):1001-1009

AlQuaiz AJM, Kazi A, Al Muneef M (2013) Determinants of sexual health knowledge in adolescent girls in schools of Riyadh-Saudi Arabia: a cross sectional study. BMC Womens Health 13:19

Anderst J, Kellogg N, Jung I (2009) Reports of repetitive penile-genital penetration often have no definitive evidence of penetration. Pediatrics 124(3):e403-e409

Bays J (1993) Medical diagnosis of the sexually abused child. Child Abuse Negl 17(1):91-110

Bottoms BL, Goodman GS, Schwartz-Kenney BM, Thomas SN (2002) Understanding children's use of secrecy in the context of eyewitness reports. Law Hum Behav 26(3):285-313

Cederborg A-C (2004) Factors influencing child witnesses. Scand J Psychol 45(3):197-205

Dion J, Cyr M (2008) The use of the NICHD protocol to enhance the quantity of details obtained from children with low verbal abilities in investigative interviews: a pilot study. J Child Sex Abus 17(2):144-162

Finkelhor D (1994) The international epidemiology of child sexual abuse. Child Abuse Negl 18(5):409-417

Goodman GS, Batterman-Faunce JM, Schaaf JM, Kenney R (2002) Nearly 4 years after an event: children's eyewitness memory and adults' perceptions of children's accuracy. Child Abuse Negl 26(8):849-884

Hershkowitz I, Sternberg KJ, Boat B, Everson MD (1996) Investigative interviews of alleged sexual abuse victims with and without anatomical dolls. Child Abuse Negl 20(12:1251-1259

Kenny MC, McEachern AG (2000) Racial, ethnic, and cultural factors of childhood sexual abuse: A selected review of the literature. Clin Psychol Rev 20(7):905-922

Lamb ME, Orbach Y, Hershkowitz I, Esplin PW, Horowitz D (2007) A structured forensic interview protocol improves the quality and informativeness of investigative interviews with children: A review of research using the NICHD Investigative Interview Protocol. Child Abuse Negl 31(11-12):1201-123.1

Orbach Y, Lamb ME (2001) The relationship between within-interview contradictions and eliciting interviewer utterances. Child Abuse Negl 25:323-333

Orbach Y, Hershkowitz I, Lamb ME, Sternberg KJ, Esplin PW, Horowitz D (2000) Assessing the value of structured protocols for forensic interviews of alleged child abuse victims. Child Abuse Negl 24(6):733-752

Pereda N, Guilera G, Forns M, Gómez-Benito J (2009) The international epidemiology of child sexual abuse: a continuation of Finkelhor (1994). Child Abuse Negl 33(6):331-342

Pietrantonio AM, Wright E, Gibson KN, Alldred T, Jacobson D, Niec A (2013) Mandatory reporting of child abuse and neglect: crafting a positive process for health professionals and caregivers. Child Abuse Negl 37(2-3):102-109

Poole DA, Dickinson JJ (2011) Evidence supporting restrictions on uses of body diagrams in forensic interviews. Child Abuse Negl 35:659-669

Roberts KP, Powel MB (2001) Describing individual incidents of sexual abuse: a review of the research on the effect of multiple sources of information on children's reports. Child Abuse Negl 25(12):1643-1659 
Saywitz K, Camparo L (1998) Interviewing child witnesses: a developmental perspective. Child Abuse Negl 22(8):825-843

Sternberg KJ, Lamb ME (1997) Effects of introductory style on children's abilities to describe experiences of sexual abuse. Child Abuse Negl 21:1133-1146

Stoltenborgh M, van ljzendoorn MH, Euser EM, Bakermans-Kranenburg MJ (2011) A global perspective on child sexual abuse: meta-analysis of prevalence around the world. Child Maltreat 16(2):79-101

Ann E. Tobey, Gail S. Goodman (2010) Children's eyewitness memory: Effects of participation and forensic context. Child Abuse Negl 1992 NovemberDecember; 16 (6):779-796

Varese F, Smeets F, Drukker M, Lieverse R, Lataster T, Viechtbauer W et al (2012) Childhood Adversities Increase the Risk of Psychosis: A Meta-analysis of Patient-Control, Prospective- and Cross-sectional Cohort Studies. Schizophr Bull 38(4):661-671

\section{Submit your manuscript to a SpringerOpen ${ }^{\odot}$ journal and benefit from:}

- Convenient online submission

- Rigorous peer review

- Open access: articles freely available online

- High visibility within the field

- Retaining the copyright to your article

Submit your next manuscript at $>$ springeropen.com 